\title{
Research Paper \\ Effectiveness of Group Cognitive-Behavioral Therapy on Strategies for Coping with Stress of Family Caregivers of Patients with Alzheimer's Disease
}

\author{
Masoumeh Mahmoodi ${ }^{1}$, ${ }^{*}$ arvaneh Mohammad Khani ${ }^{2}$, Bagher Ghobari Banab ${ }^{3}$, Fariborz Bagheri ${ }^{1}$ \\ 1. Department of Psychology, Science and Research Branch, Islamic Azad University, Tehran, Iran. \\ 2. Department of Clinical Psychology, University of Social Welfare and Rehabilitation Sciences, Tehran, Iran. \\ 3. Department of Psychology and Exceptional Children's Education, Faculty of Psychology and Educational Sciences, University of Tehran, Tehran, Iran.
}

Citation: Mahmoudi M, Mohammad Khani P, Ghobari Banab B, Bagheri F. [The effectiveness of group cognitive-behavioral therapy on strategies for coping with Stress of family caregivers of patients with Alzheimer disease (Persian)]. Iranian Journal of Ageing. 2016; 11(4):190-201. http://dx.doi.org/10.21859/sija-1101190

: http://dx.doi.org/10.21859/sija-1101190

Received: 06 Oct. 2015 Accepted: 18 Feb. 2016

\section{A B ST RACT}

Objectives Alzheimer's disease is a progressive and degenerative disease of the brain that severely damages the thinking and memory functions of human beings. This disease is the most common form of dementia, which comprises a set of signs and symptoms such as loss of memory, judgment, and reasoning that subsequently changes the attitude, behavior, and communication ability.

Taking care of people with Alzheimer's disease can become very stressful for their families. Group cognitivebehavioral therapy has played an important role in teaching how to use compatible coping strategies. Thus, this research aimed to investigate the effectiveness of group cognitive-behavioral therapy on strategies for coping with stress of family caregivers of patients with Alzheimer's disease.

Methods \& Materials This research was conducted using a quasi-experimental design. The study sample comprised 32 voluntary caregivers as per Iran's Alzheimer Community Care in 2011. They were selected by convenience sampling method and were randomly assigned into experimental and control groups. We used the questionnaire of coping inventory with stressful situations (CISS), which was completed before group therapy and after the treatment course in 3 stages of pretest, posttest, and follow-up. Data analysis was performed by analysis of covariance, multivariate analysis of covariance, and repeated measures.

Results The results showed that the components of compatible strategies (problem-oriented and social entertainment) in the experimental group were significantly increased compared to pretest and control group due to cognitive-behavioral therapy $(\mathrm{P}=0.001)$. However, the components of incompatible strategies (emotionoriented and attention processing) due to cognitive-behavioral therapy was significantly decreased in the experimental group compared to the pretest and control group $(\mathrm{P}=0.001)$. The results of repeated measuring plan between 3 stages of pretest, posttest, and follow-up showed that the effects of cognitive-behavioral therapy on increasing compatible coping style (problem-oriented and social entertainment) and decreasing incompatible coping style (emotion-oriented and attention processing) as well as the effect of intergroup actions and repetition were significant. There was also a significant difference between experimental group and control group. Moreover, the time factor was ineffective in lowering the effect of cognitive-behavioral therapy from posttest to follow-up period.

Conclusion Based on the results, the group cognitive-behavioral therapy can increase the use of compatible strategies for coping with stress and decrease the use of incompatible strategies. This issue is related to factors such as complete understanding of Alzheimer's disease and its effects, creating an atmosphere for presentation and an opportunity for social interaction, understanding the importance of sport and allocating time for recreational activities, learning body relaxation in stressful situations, understanding life problems, solving problem techniques, feeling of control, and time management. Thus, we recommend using group cognitivebehavioral therapy as a low-cost treatment for family caregivers of patients with Alzheimer's and patients with chronic diseases.
Alzheimer, Caregivers, Cognitivebehavioral therapy, Stress

* Corresponding Author:

Parvaneh Mohammad Khani, PhD

Address: Department of Clinical Psychology, University of Social Welfare and Rehabilitation Sciences, Kodakyar Ave., Daneshjo Blv., Evin, Tehran, Iran. Tel: +98 (21) 22180045

E-mail: parmohamir@yahoo.com 


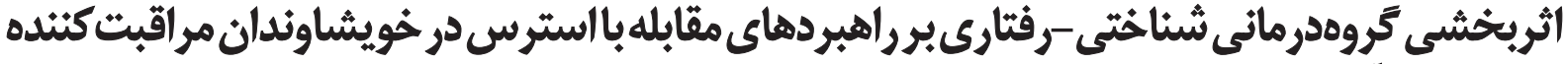 مبتلايان به ألزايمر
}

\author{
معصومه محمودى'، "•روانه محمدخانى'، باقر غبارىبناب"، فريبرز باقرى' \\ 1- ا-كروه روانشئاسى، دانشعاه آزاد اسلامى، واحد علوم و تحقيقات، تهران، ايران.

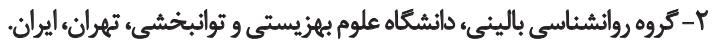

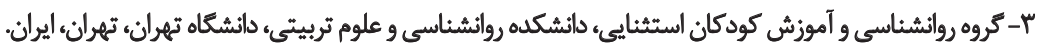

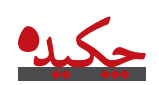

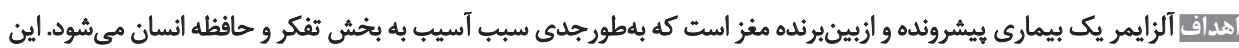

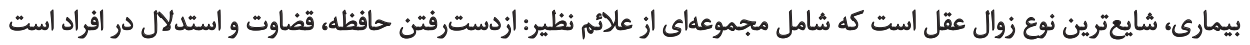

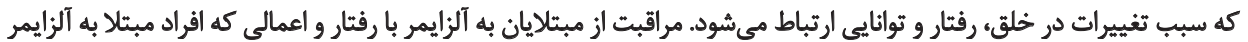

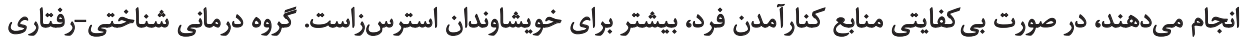

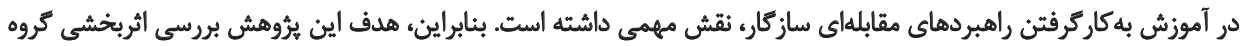

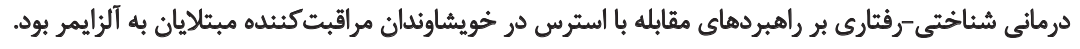

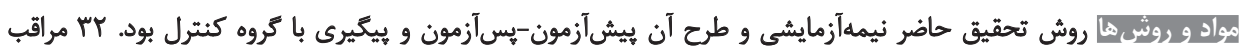

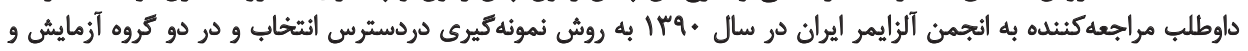

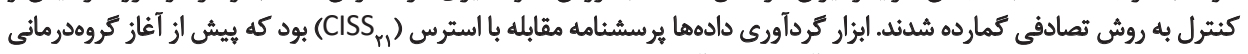

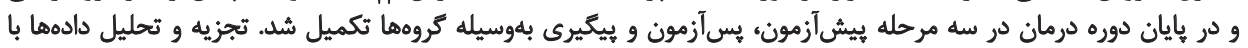

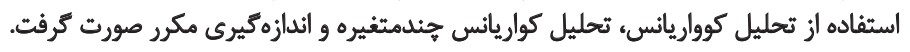

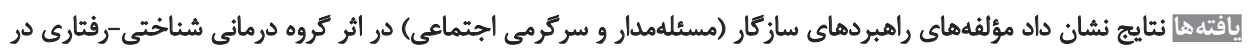

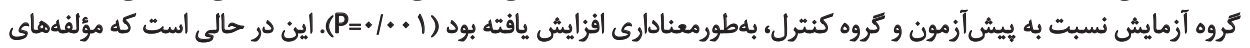

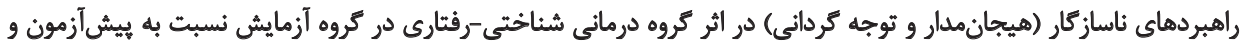

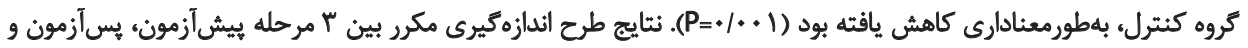

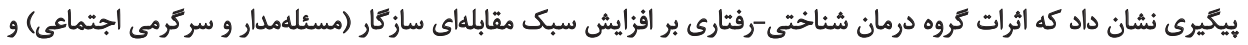

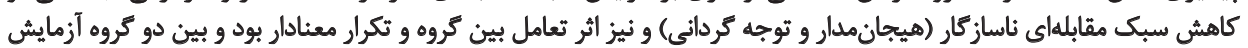

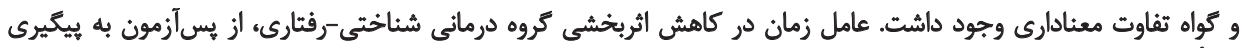
بتى تأثير بود.

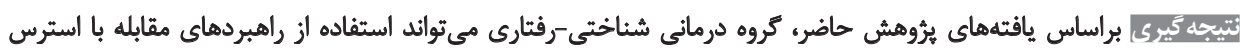

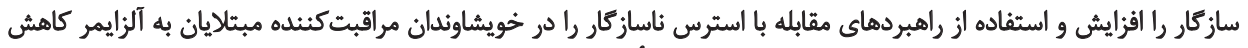

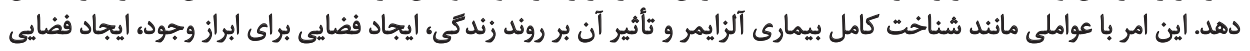

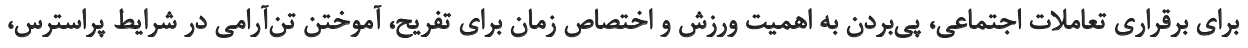

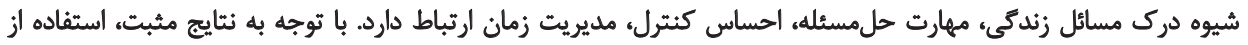

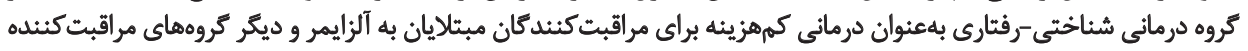

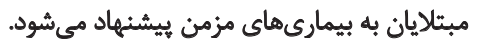

تاريخ دريافت: II

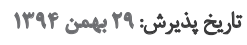

كليدواروها:

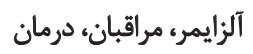
شناختى-رقتارى، استرس درن 
مى تواند آموزش داده شود و كسب اين مهارت براى حفظ سلامت

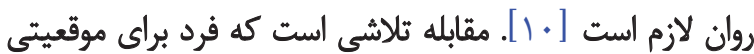

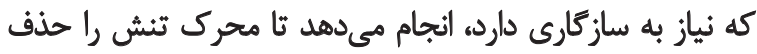

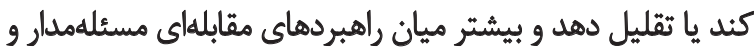

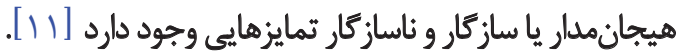
روانشئاسى سلامت، در سالهاى اخير اهميت زيادى براي

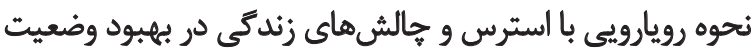

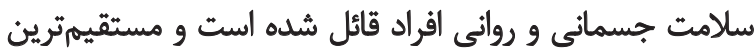

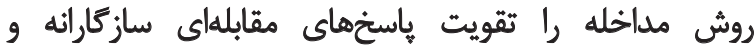

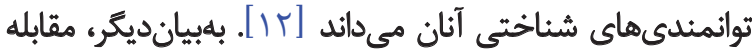

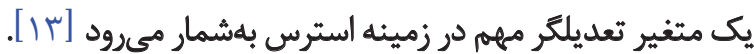

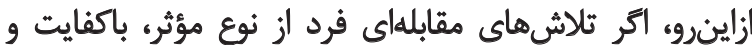

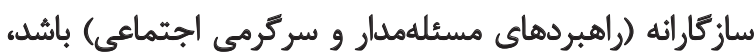

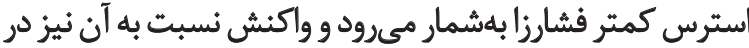
راستاى كاهش ييامدهاي منفى صورت مي مئيرد. ازسوى ديخر اتحر سبك يا الكوى مقابله، ناساز خارانه (راهبردهاى

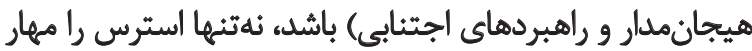

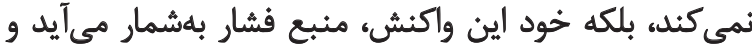

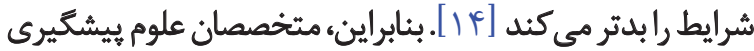

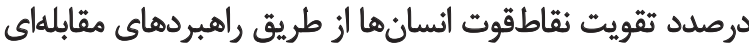

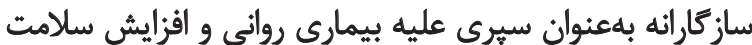

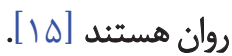

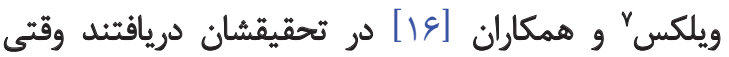

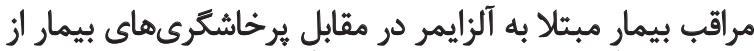

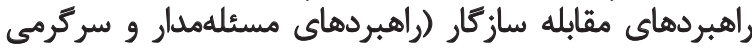

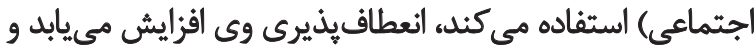

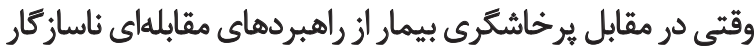

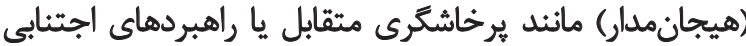

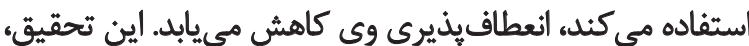

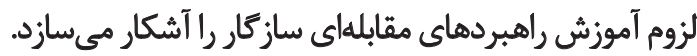
برنامههاى مداخلهاى زمانى احتمال موفقيت دارند كه مبتنىبر

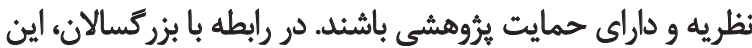

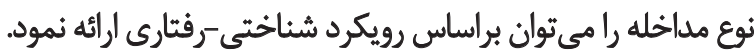

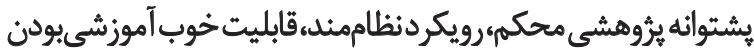

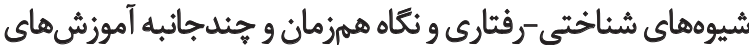

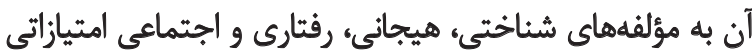

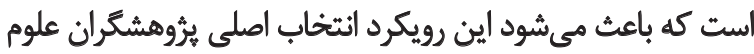

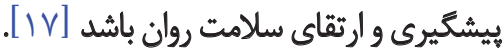
يثروهش هاى متعدد در حوزه روانشناسى سلامت تأثير مثبت
مقدمه

بيمارى آلزايمر،شايعترين نوعدمانساستوبيشترباكنارهكيرى

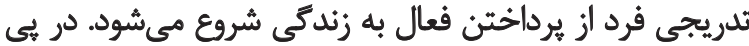

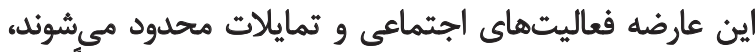

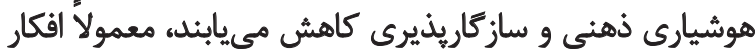

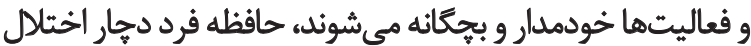

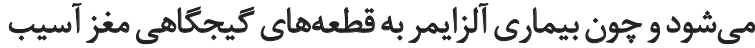

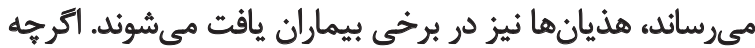

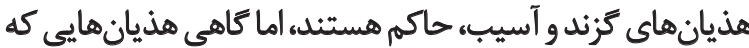

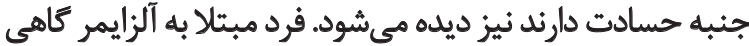

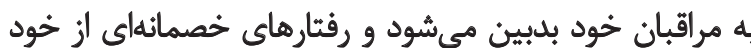

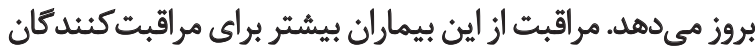

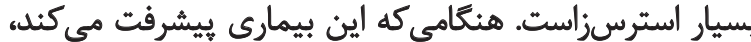

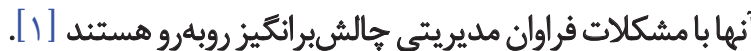
يثروهش هايى كه در زمينه مراقبت كنندكان خويشاوند مبتلايان

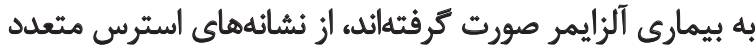

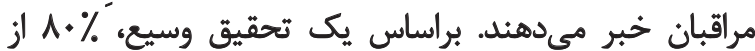

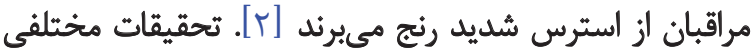

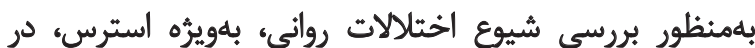

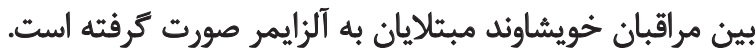

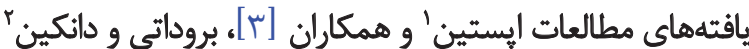

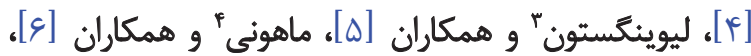

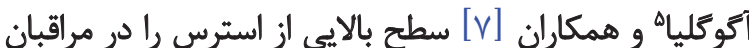

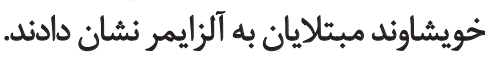

ويتالينو و كاتون" [A] با انجام فراتحليلى روى Af مقاله

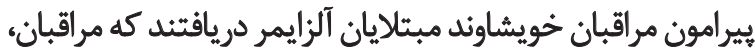

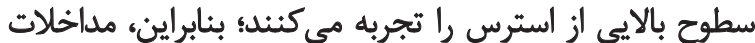

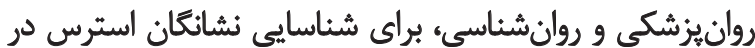

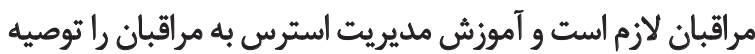

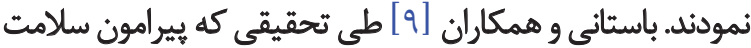

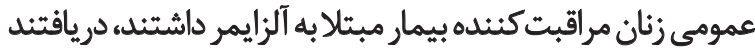
كه مراقبان در وضعيت مطلوبى از سلامت عمومى قرار نداشتيتند. اين حقيقت قابل ذكر است كه استرس، غالبأ تجربهاي است كه فر فرد

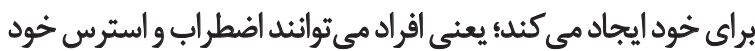

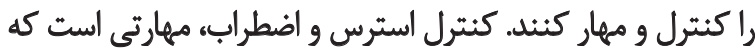

1. Epstin

2. Brodaty and Donkin

3. Livingston

4. Mahoney

5. Aguglia

6. Vitaliano and Katon 
روش مطالعه

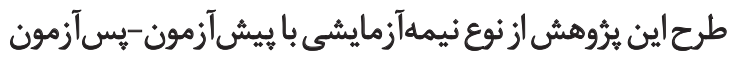

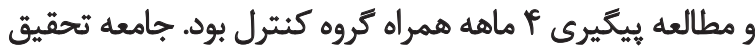

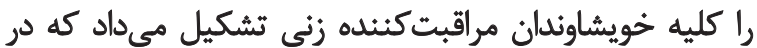

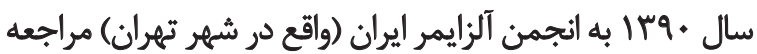

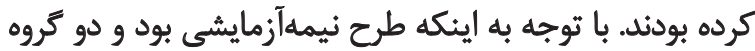

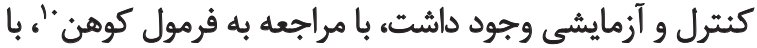

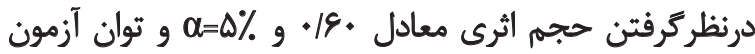

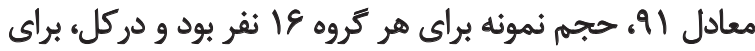

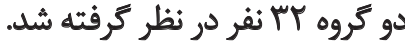

براى انتخاب نمونه، يّ از تكميل يرسشئامه توسط مراقبان

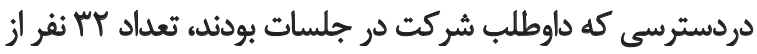

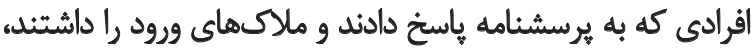

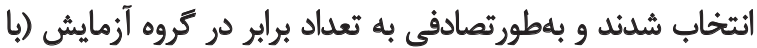

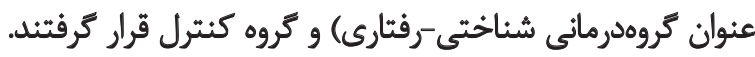

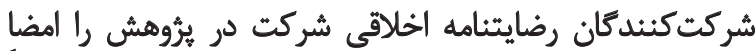

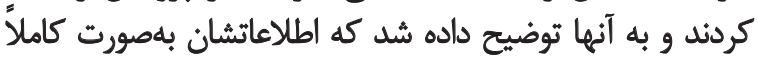

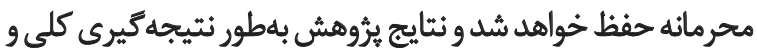

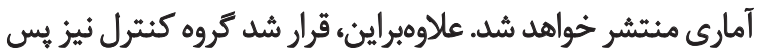

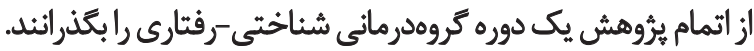

ملاكهاى ورود به روند مطالعه عبارت بودند از: إ- مراقبان

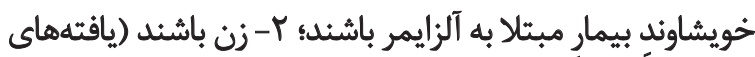

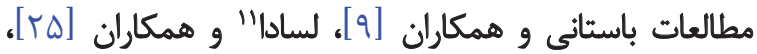

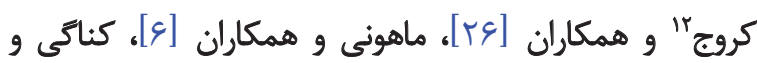

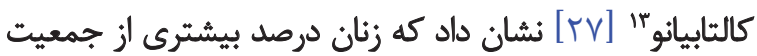

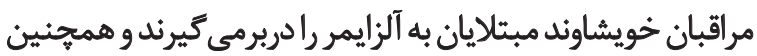

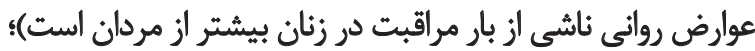

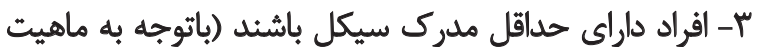

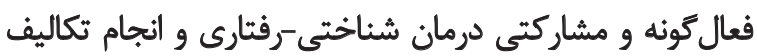

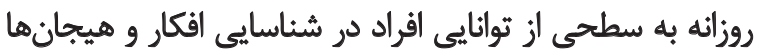

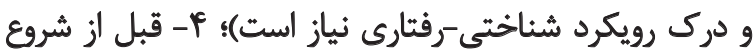
مراقبت، افراد سابقه بيمارى روانى نداشته باشنئد

بلمنظور سنجش راهبردهاى مقابله مراقبت كنئدكان فرم ئرمان

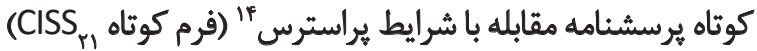

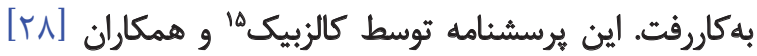

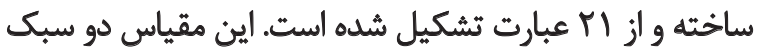

\section{Cohen}

11. Losadaa

12. Crooga

13. Conaghy and Caltabiano

14. Coping inventory for stressful situations

15. Calsbeek
استفاده از راهبردهاي مقابلهايى سازكار مانثد مديريت استرس

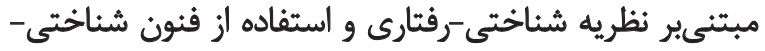

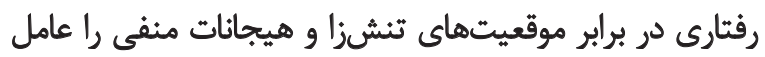

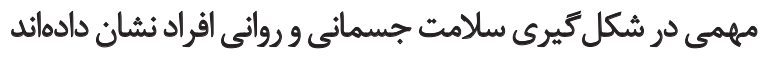

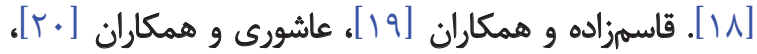

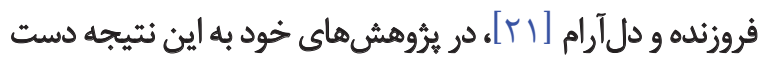

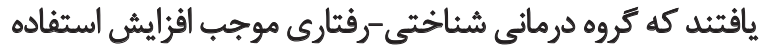

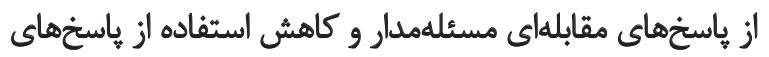

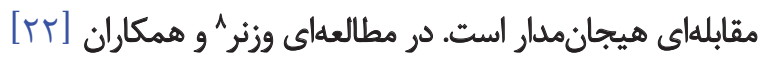

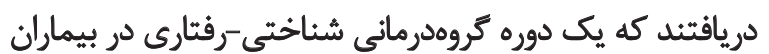

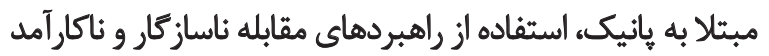

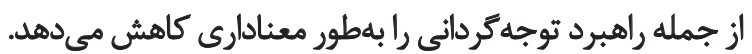

هامدان" [ [بr] طى مطالعهايى اثربخشى مداخله شناختى

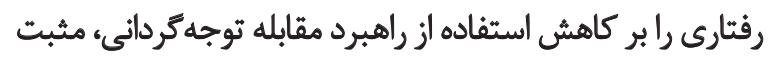

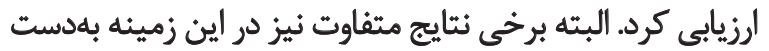

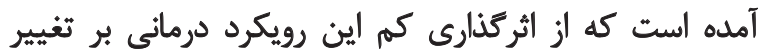

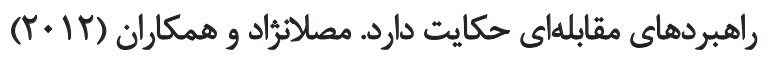

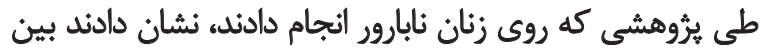

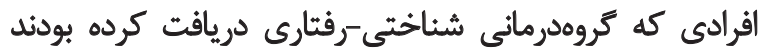

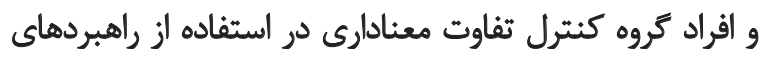

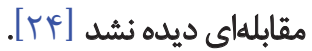

با توجه به نتيجه تحقيقاتى كه حكايت از شدت فشار روانى

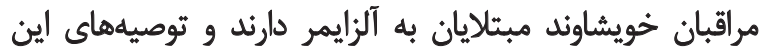

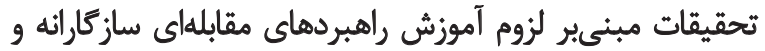

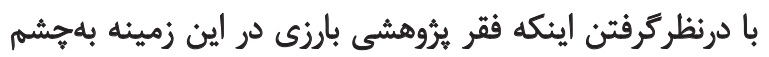

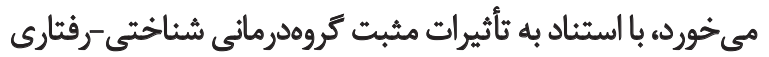

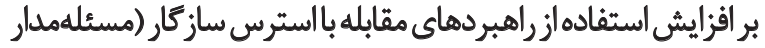

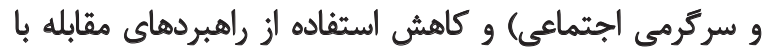

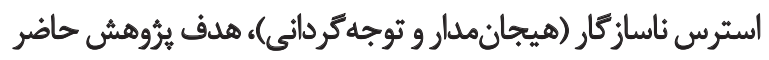

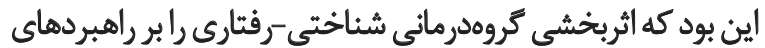

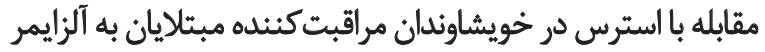

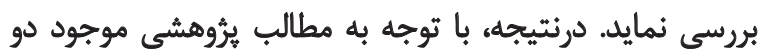
فرضيه اصلى براي انجام تحقيق حاضر مدنظر قرار كرفت: •كروهدرمانى شناختى -رفتارى در خويشاوندان مراقبت كنينده

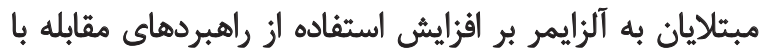

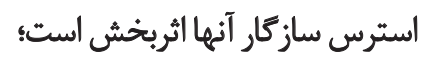
•كروددرمانى شناختى -رفتارى در خويشاوندان مراقبت كنينده

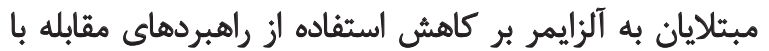
استرس ناسازكار آنها اثربخش است. 
شناخت افكار غيرمنطقى و توضيح درباره خطاهاى شناختى و نقش آنها در ايجاد استرس؛

جلسه ششم: آموزش ارزيابي مجدد افكار و جالش بارئ افكار بهنوان راهكارى براى بلمبارزمطلبيدن افكار غيرمنطقي؛ جلسه هفتم: آموزش مديريت زمان با آموختن هدف كذارى،

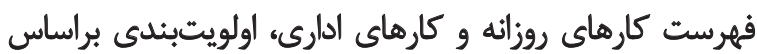

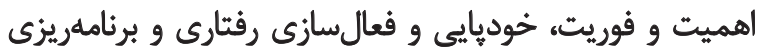
هفتگى موانع مديريت زمان؛

جلسه هشتم: آموزش حلمسئله و واكنش مناسب در مقابل

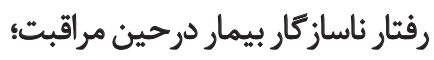

جلسه نهم: آموزش مديريت خشهم و انجام تمرينهاى مربوط به راههاى كنترل خشم و شيوه صحيح ابراز نار احتى؛ جلسه دهم و يازدهم: آموزش راههاى افزايش اعتمادبهنفس؛

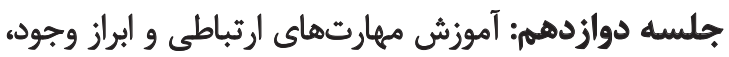

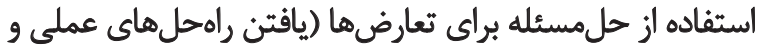

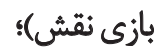

جلسه سيزدهم: توضيح در مورد انواع حمايت اجتماعي و

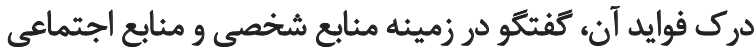

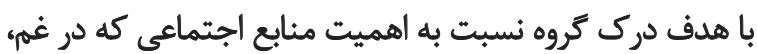
بيشرفت و... به فرد كمك سازنده مي كندئ جلسه جههاردهم: مرور كلى و تمرين مهارتهاي آموختهشده

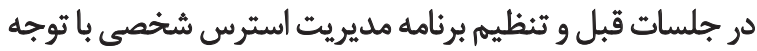

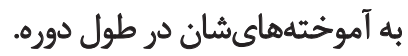
درمانكر در هر جلسه ابتدا موارد موردبحث را مشخص و و درئ

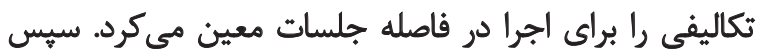

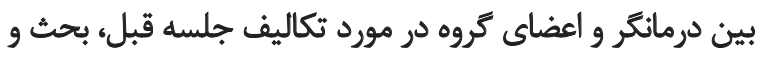

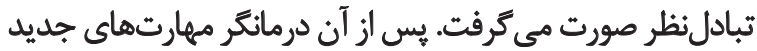

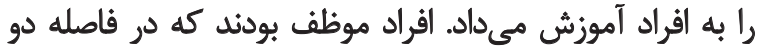

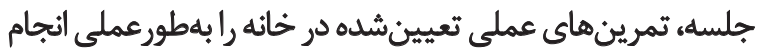

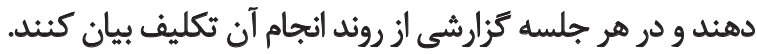

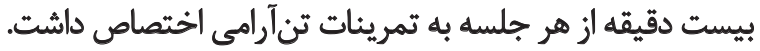

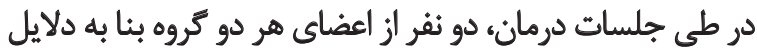
شخصى به همكارى خود ادامه ندادند.

دريايان، دادههاى بهدست آمده از يرسشنامه راهبردهاى مقابله

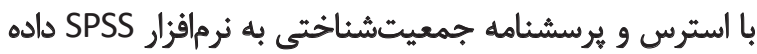

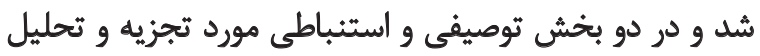

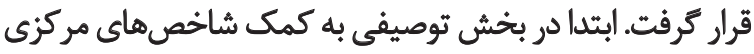

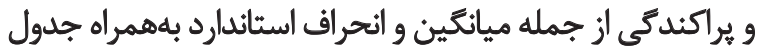

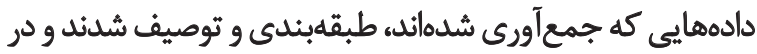

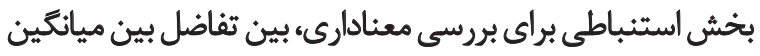

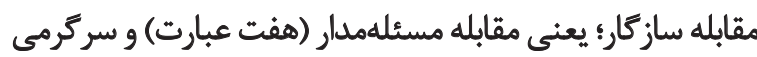
اجتماعى (سه عبارت) و دو سبك مقابله ناسازكاري؛ يعنى مقابله

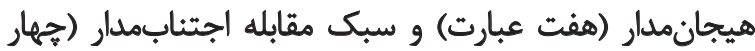

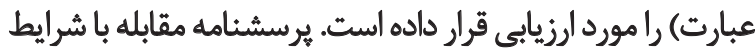

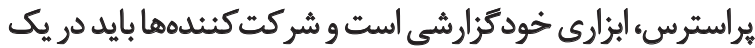

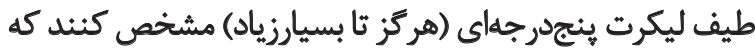

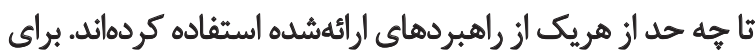

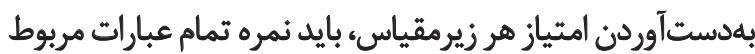

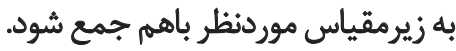

نتايج يثروهشها نشان داده است كه زيرمقياسهاى مقابعايله

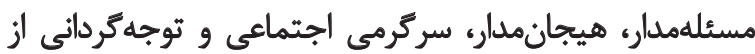

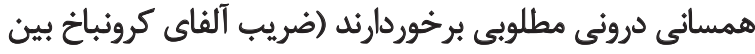

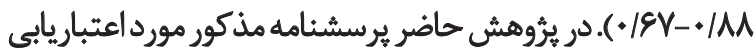

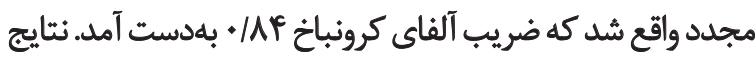

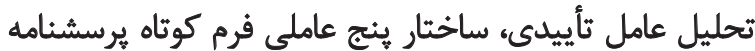

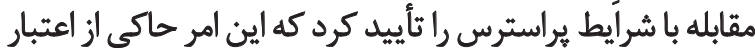

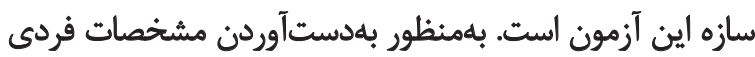

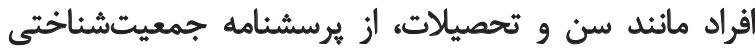
محققساخته استفاده شد.

جلسات درمانى شامل If جلم جله بود كه هر هفته يكبار

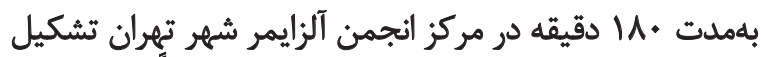

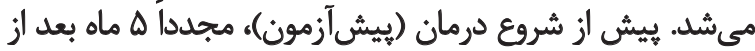

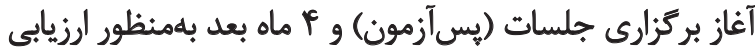

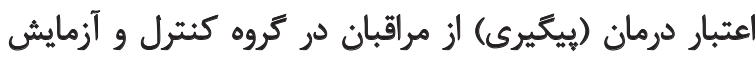

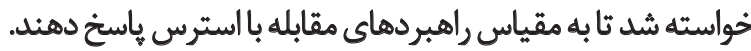
جلسات كروهدرمائى شناختى -رفتارى توسط محقق براى كروه

$$
\text { آزمايش به شرح زير بود: }
$$

جلسه اول: آشنايي با اعضا و بيان منطق و اهداف جلسات

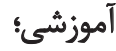

جلسه دوم: بحث درباره بيمارى آلزايمر و تأثير آن بر روند

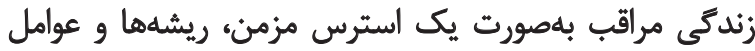

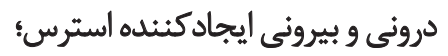
جلسه سوم: تعريف استرس و مقابلههاى سازكارانه و آموزش ير ئري

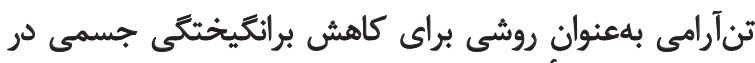

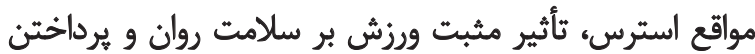

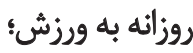

جلسه جهارم: مشكل تشايى و طرح مسئله، شيوه درى

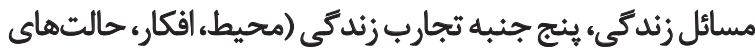

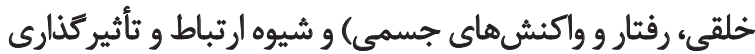

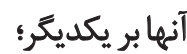

جلسه ينجم: تشخيص و درجهبندى حالات خلقى، راههاى 


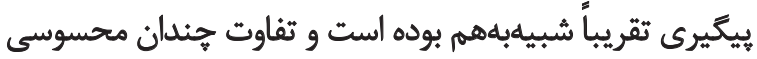

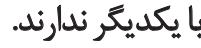

نتايج تحليل كوواريانس جندمتغيرى (مانكووا) براى مقايسه اثر دو

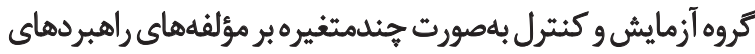

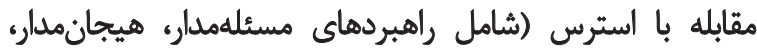

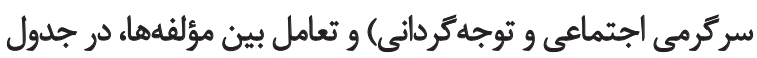

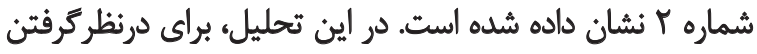

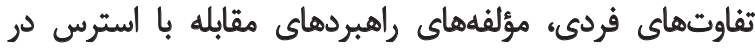
يشي آزمون بهعنوان متغير هاى همراه وارد تحليل شدهاندان براي بررسى معنادارى تحليل از جهار آزمون اثي ييلايي، لامبداي

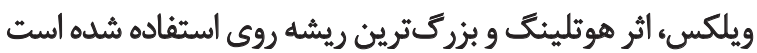

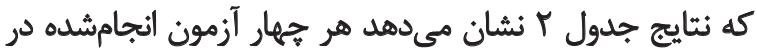

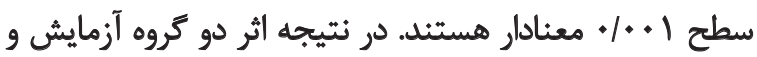

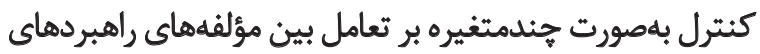

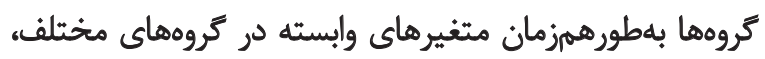

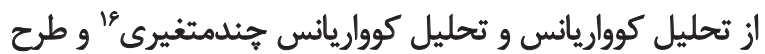

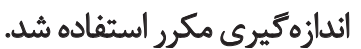

يافتهها

اطلاعات جدول شماره 1 نشان مىدهد ميانكين نمرات

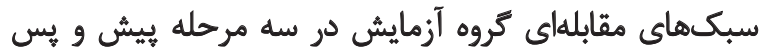

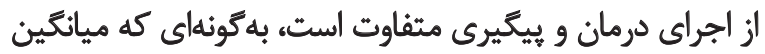

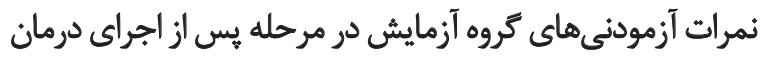

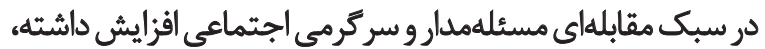

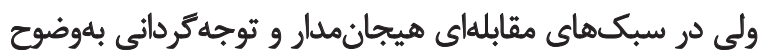

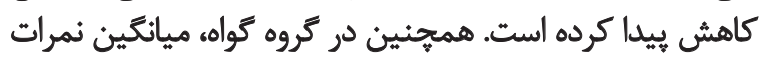

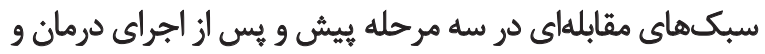

16. MANCOVA

جدول ا. ميانكين و انحراف معيار سبكهاى مقابلهاي در بيش آزمون، بسأزمون و

\begin{tabular}{|c|c|c|c|c|c|}
\hline \multicolumn{2}{|c|}{ كروه كُواه } & \multicolumn{2}{|c|}{ كروها آزمايش } & \multirow{2}{*}{ هرهله } & \\
\hline انحراف معيار & مياتكين & انحراف معيار & مياتكَين & & \\
\hline T/H & $\mid F / M$ & $T / M$ & $\mid Q / N E$ & ييش آزمون & \multirow{3}{*}{ مسثلهملار } \\
\hline g/NF & $|F / r|$ & $r / A r$ & Tq/Tg & يسآزمون & \\
\hline $1 / T \Delta$ & NEq & thef & $r \cdot / \mu r$ & ييكيري & \\
\hline $8 / 9 Y$ & rथाF & $8 / . V$ & TV/RT & ييش آززمون & \multirow{3}{*}{ هيجانهملار } \\
\hline $8 / \Delta$ & TYRTI & T/৭८ & $10 / 9$ & يسآزيهون & \\
\hline$r / \Delta A$ & MVAs & .180 & No. & ييكيرى & \\
\hline$m / s$. & $q /{ }^{2} \Delta$ & efro & $N \cdot \Lambda$ & ييشآزمهون & \multirow{3}{*}{ سركرمى اجتماعى } \\
\hline$M / T$. & NAT & $M T$ & $|r / T|$ & يس آزّمون & \\
\hline $1 / 9$. & $\Delta / 48$ & $M / m$ & $11 / \Delta V$ & ييكيرى & \\
\hline$\Delta / F$ & $N N_{1}$ & $\Delta / q \mu$ & Ir/Wg & ييش آزمون & \multirow{3}{*}{ توجه كرداني } \\
\hline$F / M$ & $1 . / \pi 1$ & $T / M F$ & S/ME & يسأزمون & \\
\hline V/8 & $\mid Q / \Delta F$ & We. & $\Delta / H T$ & ييكيرى & \\
\hline
\end{tabular}

L

جدول ז. آزمون تحليل كوواريانس جيندمتغيرى براى مثايسه اثر جيندمتغيره كروهاى آزمايش و كنترل بر تعامل مؤلفههاى راهبردهاى مقابله با استرس.

\begin{tabular}{|c|c|c|c|c|c|}
\hline سطح معنادارى & درجه آزادى r & درجه آزادى I & $F$ & آماره & آزمون \\
\hline $.10+$ & iv & $f$ & ArfTe & $\cdot 1 N$ & اثر ييلاليى \\
\hline .1. & IV & $p$ & Afre &.$/ M$ & لامبداي ويلكز \\
\hline$\%$ & IV & $r$ & AfRe & MVE & اثر هثلينى \\
\hline$\%$ & IV & $f$ & AF/TE & mis & بزرىترين ريشه روى \\
\hline
\end{tabular}


جدول گr. تحليل كوواريانس مؤلفههاي راهبردهاي مقابله با استرس در بسآزمون.

\begin{tabular}{|c|c|c|c|c|c|c|c|}
\hline مجذور أثا & سطح معنادارى & $F$ & مياتكين مجذورات & درجه آزادى & مجموع مجذورات & مثبع & مؤلفه \\
\hline.$/ M A$ & $+\infty$ & $9 / 11$ & $118 / \pi f$ & 1 & $118 / \pi$ & ييش آزمهون & \\
\hline \multirow[t]{2}{*}{$\cdot M^{m}$} & $*$ & ENTA & $11+/ M^{2}$ & 1 & $11 \cdot / \pi r$ & كروه & مسئلهمبار \\
\hline & .1. & & II/AY & TA & ras/vg & حُطا & \\
\hline . pen & .1. & TYND & $r \cdot 1 / h^{e}$ & 1 & $r \cdot 1 / M^{e}$ & ييش آزآهون & \\
\hline \multirow[t]{2}{*}{. NS } & .1. & $W / A$. & $1 .+\infty \Delta / . r$ & 1 & $1 . F a / . r$ & $\Delta$ & هيجان مدار \\
\hline &.$\%$ & & Ir/Te & 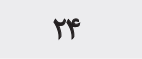 & MWTF & خطا & \\
\hline.$/ \mu P$ & .1. & 19 & $V D / F)$ & 1 & $V Q / F)$ & ييش أزهون & \\
\hline \multirow[t]{2}{*}{.180} & .1. & Prina & IVND. & 1 & IVNA. & Sر & سرك مي اجتماعي \\
\hline & .1. & & r/ar & $M$ & $9 \Delta / 0$ & خطا & \\
\hline . & .1. & $I r / \Delta A$ & $|M T / K|$ & 1 & $|M T / T|$ & ييش أزمون & \\
\hline \multirow[t]{2}{*}{.$/ A T$} & +1. & $19 / 8$. & $19 \cdot / 1$. & 1 & $19 \cdot 11$. & كروه & توجهكرداني \\
\hline & & & $q / r^{m}$ & TA & THT/ME & خطا & \\
\hline
\end{tabular}

乩

جدول F. ميانكينهاى تعديلشده مؤلفههاى راهبردهاى مقابله با استرس در كروههاى مختلف در يس آزمون.

\begin{tabular}{|c|c|c|c|c|c|}
\hline \multicolumn{2}{|c|}{ فاصله اطمينان \%ه } & \multirow[b]{2}{*}{ خطاى معيار } & \multirow[b]{2}{*}{ ميائكين } & \multirow[b]{2}{*}{ كروه } & \multirow[b]{2}{*}{ متثير } \\
\hline حد بالا & حد باييين & & & & \\
\hline$r V / V I$ & rm/Ae & . & $r \Delta / V A$ & أزمايشي & \multirow[b]{2}{*}{ مسئلهمدار } \\
\hline jejew & & & & 10.5 & \\
\hline & & & & & \\
\hline IV/TY & $17 / 19$ & +/9V & $|Q / Y|$ & أزمايش & \multirow{2}{*}{ هيجانملار } \\
\hline rV/Ne & $\mathrm{ra/SV}$ & $y / 1$ & $T V / W$ & كتترل & \\
\hline $\mid f / \Delta f^{f}$ & IT/TO &.$/ \Delta \Delta$ & $1 \% / m q$ & آزمايش & \multirow[b]{2}{*}{ سركزمى اجتماعى } \\
\hline $9 / \pi$. & $V / \cdot q$ & . $/ \Delta r$ & NT. & كتثرل & \\
\hline V/TA & $r / e V$ &.$/ N$ & $\Delta / P E$ & آزمايش & \multirow{2}{*}{ توجهكردانى } \\
\hline $1 \pi / 19$ & $q / m$ &.$/ N$ & $11 / 1$ & كتّرل & \\
\hline
\end{tabular}

跳

مؤلفه بهطورجداكانه بين كروههاى آزمايش و كنترل ثناوت

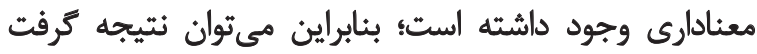

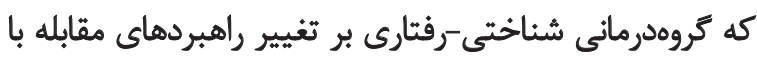

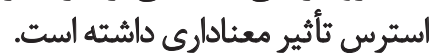

جدول شماره f ميانكين هاى تعديل شده مؤلفههاى راهبردهاى

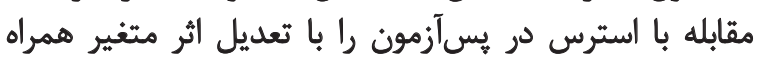

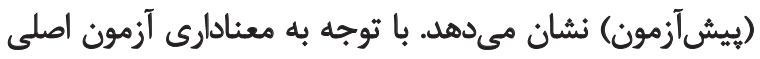

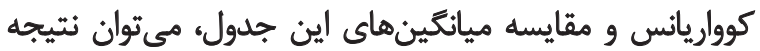

مقابله با استرس ثأثير معثادارى داشته است؛ بهعبارتديكر،

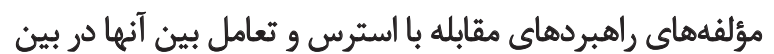
دو كروه موردمطالعه تفاوت معنادارى مارى داشتهاند. براى معايسه مؤلفههاى راهبردهاى مقابله با استرس شامل

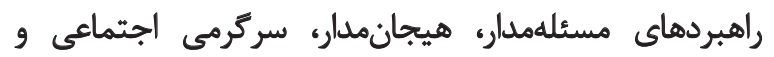

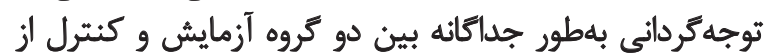

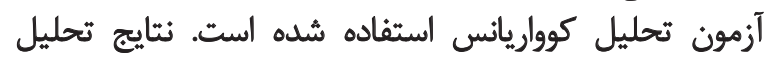

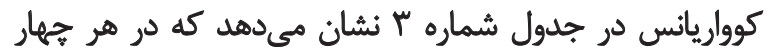


جدول ه. تحليل طرح اندازهيرى مكرر براي مؤلفههاي راهبردهاي مقابله با استرس.

\begin{tabular}{|c|c|c|c|c|c|c|c|}
\hline مجذذور اتا & مغنادارى & $F$ & مياتكَين مجذورات & درجه آزادى & مجموع مجذورات & منيع تغيير & متغير \\
\hline$+/ T V$ & $\%$ & $\mid f / e r$ & $10 \cdot / M F$ & $r$ & $r+.189$ & عامل تكرار & \\
\hline \multirow[t]{2}{*}{$\cdot M$} & .10 & $\Delta Q / N$ & gre/.r & $r$ & IMEN.V & "تكرار توره & مسئلهملار \\
\hline & .1 .0 & & $1 . / P r$ & in & $\Delta . . / T \Delta$ & خططا & \\
\hline.$|f|$ & 1. & $19 / \pi$ & TEAMT & r & ATNTE & عامل تكرار & \\
\hline \multirow[t]{2}{*}{$\cdot M r$} & +1. & ET/1Q & I.YNIT & r & $r+\Delta F / M r$ & "تكرار كروه & هيجان مدار \\
\hline & .1. & & $\mid \& / T \wedge$ & pe & VPNAV & خطا & \\
\hline.$/ T \Delta$ & $.1 \%$ & V/ar & $r A / F i$ & r & $9 \cdot / A r$ & عامل تكرار & \\
\hline \multirow[t]{2}{*}{.$/ \pi r$} & $\%$ & $I V / \Delta q$ & $1 \ldots / M r$ & r & $r+1 / R+e$ & "تكرار كروه & سركرمي اجتماعي \\
\hline & & & $\Delta / N$ & is & rer/F. & خطا & \\
\hline$+/ 1 \Delta$ & \% r r & $r / \pi r$ & TEIAY & r & $9 \Psi / V f$ & عامل تكرار & \\
\hline \multirow[t]{2}{*}{ - /ar } & $\%$ & TNAY & $m \mid g / r$. & $r$ & STI/FI & *تكرار كروه & توجهكردانى \\
\hline & & & $11 / .8$ & \&A & AMI/TH & خطا & \\
\hline
\end{tabular}

䂪

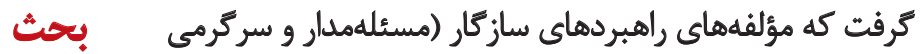

همانطوركه در مقدمه بلطور كامل اشاره شده با توجه به نتايج

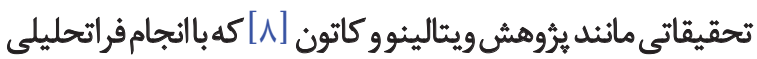

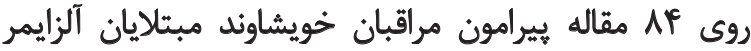

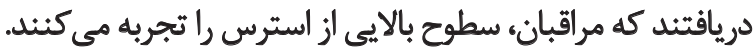

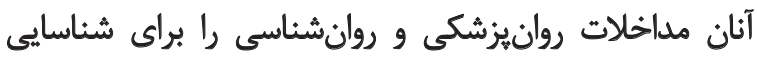

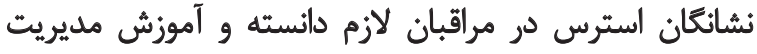

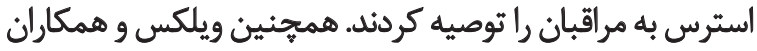

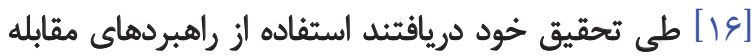

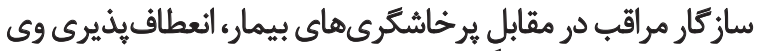

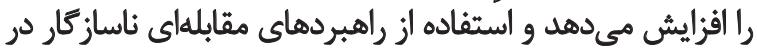

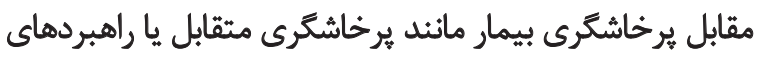

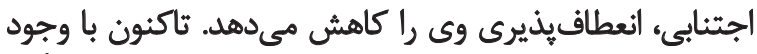

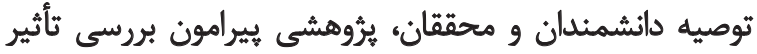

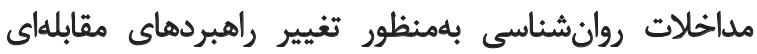

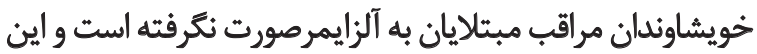

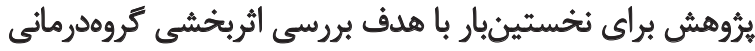

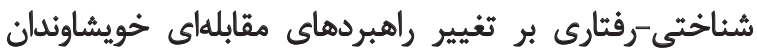

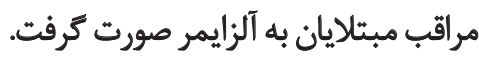

نتايج نشان داد كه كروهدرمانى شناختى -رفتارى باعث افزايش

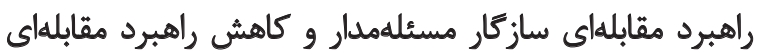

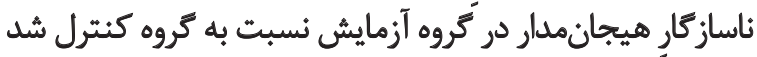

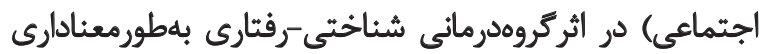

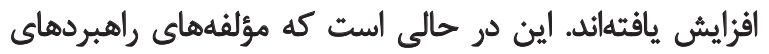

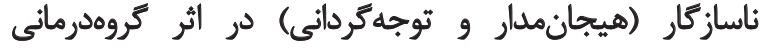
شناختى -رفتارى بهطورمعنادارى كاهش يافتئهاندا براى بررسى معنى دارى تفاوت بين تروههاى آزمايش و كنترل

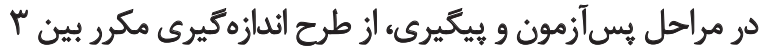

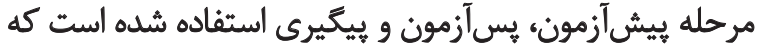

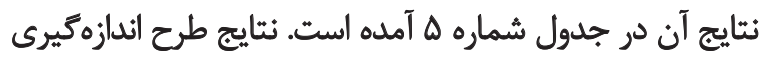

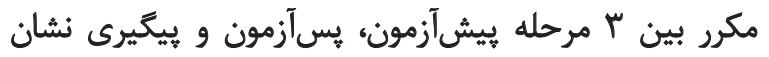

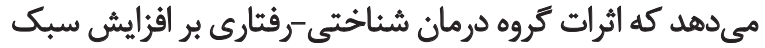

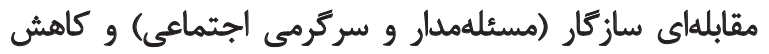

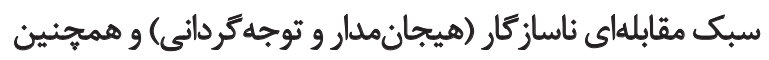
اثر تعامل بين كروه و تكرار معنادار است واست و بين دو كروهار آزمايش و كواه تفاوت معنادارى وجود دارد.

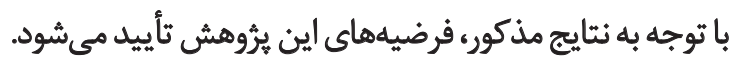

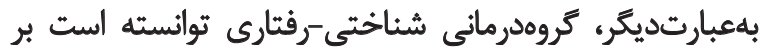

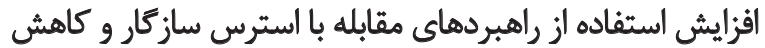

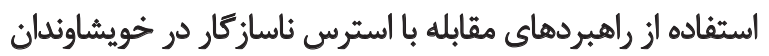

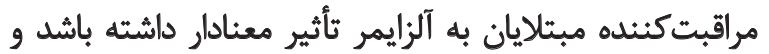

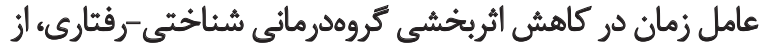
بس آزمون به يُيگيرى اثر نداشته است كرون. 
در اين هُروهش بهطوركروهي صورت كرفت. گروه موقعيتى را

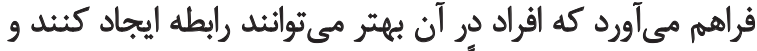

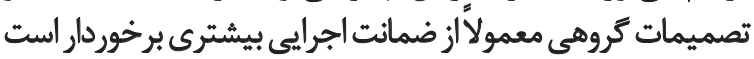

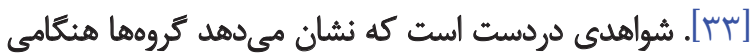

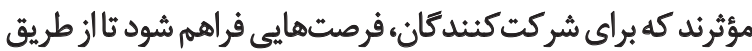

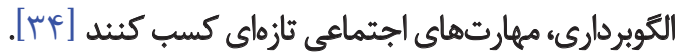

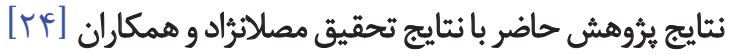

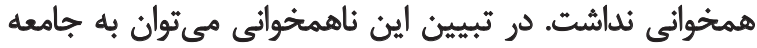

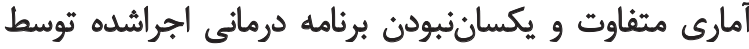

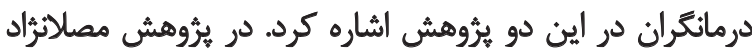

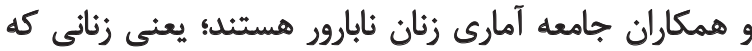

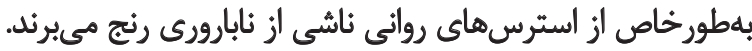

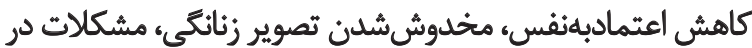

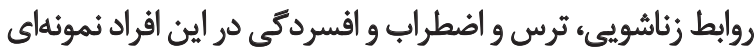

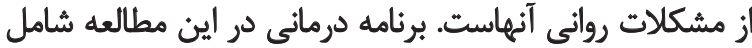

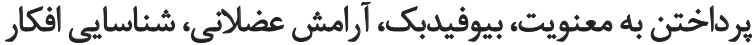

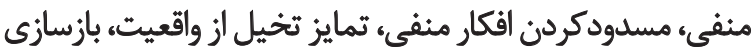

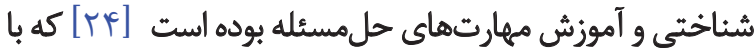

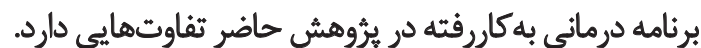

\section{نتيجهيَيرىنهايي}

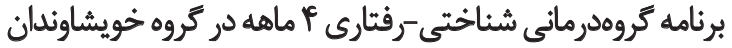

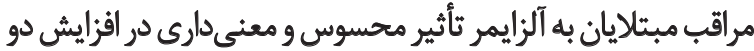

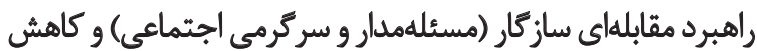

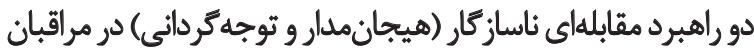

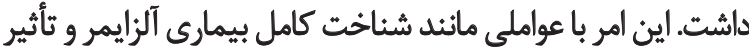

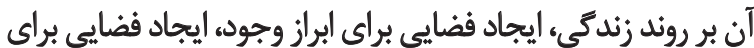

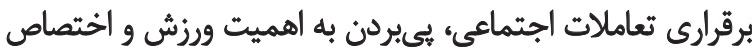

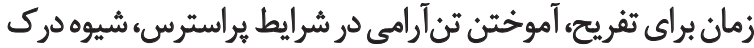

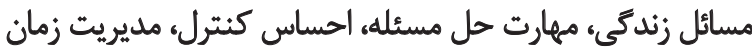

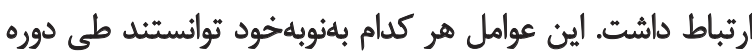

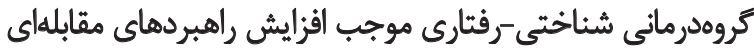

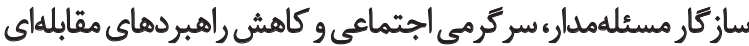

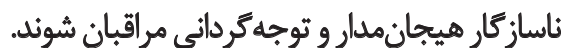

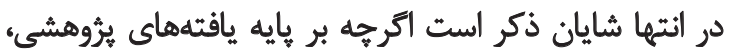

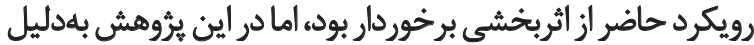

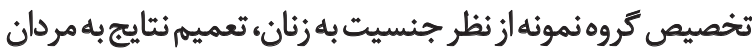

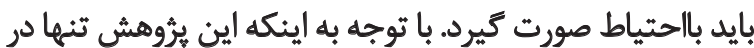

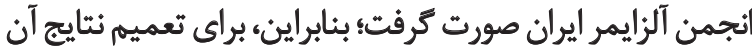

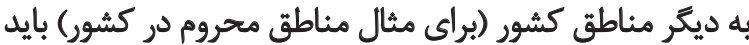

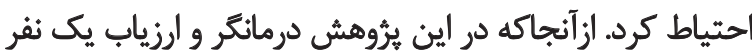
بودند (با وجودى كه نظر شخصى درمانتر اعمال نشده است)،

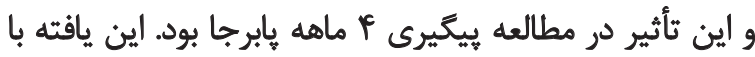

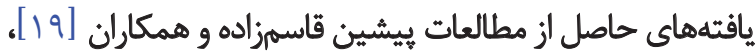

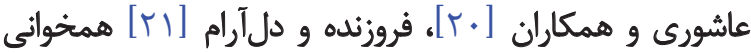

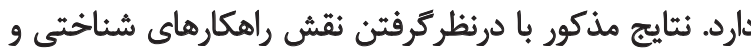

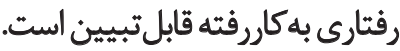

مقابله كارآمد به مهارتهايى نظير تفكر سازنده، انعطاف در

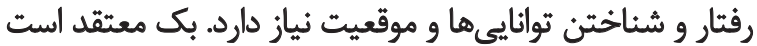

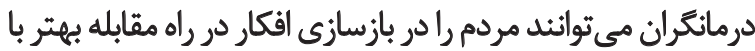

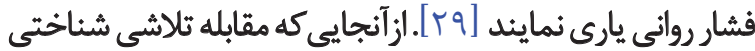

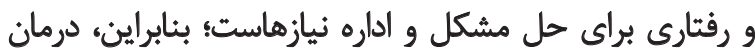

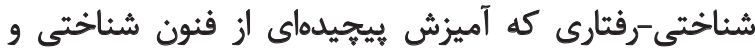

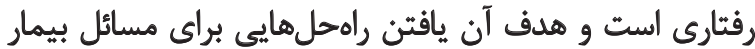
است، مى تواند در اصلاح اين شيوهها مؤثر باشد [ـــ]. همجنين نتايج نشان داد كه كروهدرمانى شناختى رفتاري

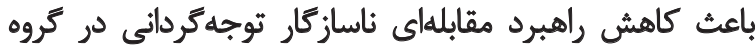

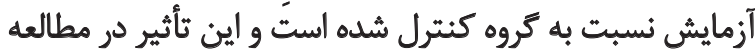

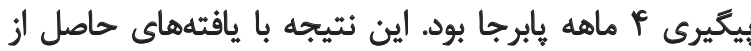

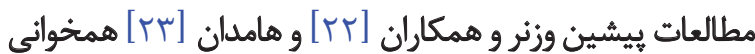

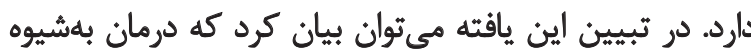

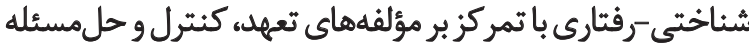
باعث افزايش سرسختى مى شئود. درحقيقت، ايجاد ارزيابىهاى واقعبينانه و شناخت مناسب

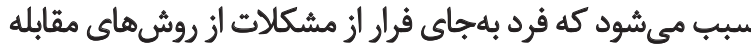

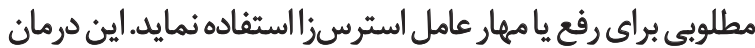

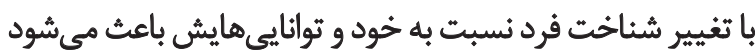

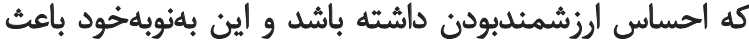

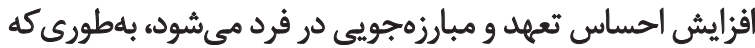

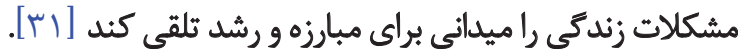

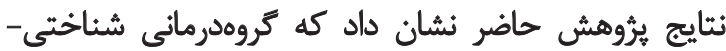

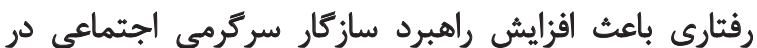

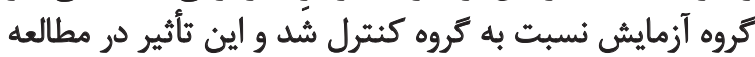

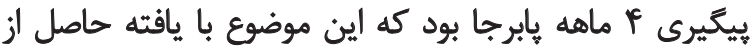

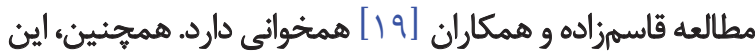

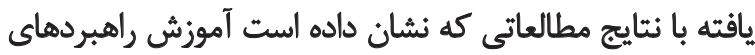

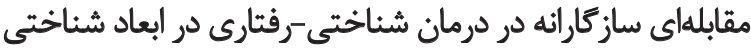

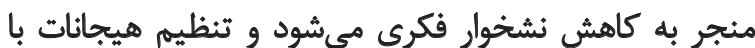

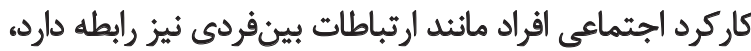

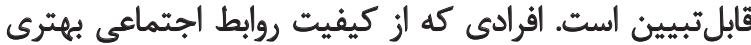

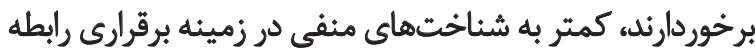

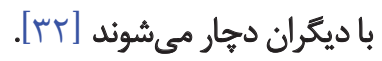

ازسويديكر، در تبيين نتايج اين تحقيق ميتوان كفت درمان 


\section{References}

[1] Butcher S, Mineka J, Hooley J. Abnormal Psycholog [Y. Seyed Mohammadi, Persian trans]. $5^{\text {th }}$ ed. Tehran: Arasbaran Publication; 2009.

[2] Hosseini H, Haji Yousefi A. [The Alzheimer's Association's training complex (Persian)]. Tehran: Donyaye Taghzieh; 2010.

[3] Epstein-Lubow G, Gaudiano B, Darling E, Hinckley M, Tremont G, Kohn R, Marino LJ, et al. Differences in depression severity in family caregivers of hospitalized individuals with dementia and family caregivers of outpatients with dementia. American Journal of Geriatric Psychiatry. 2012; 20(9):815-9.

[4] Brodaty H, Donkin M. Family caregivers of people with dementia. Dialogues in clinical neuroscience. Journal of Dialogues in Clinical Neuroscience. 2009; 11(2):217-228.

[5] Livingston G, Mahoney R, Regan C, Katona C. The Caregivers for Alzheimer's disease Problems Scale (CAPS): Development of a new scale within the LASER-AD study. Age and Ageing. 2005; 34(3):287-90

[6] Mahoney R, Regan C, Katona C, Livingston G. Anxiety and depression in family caregivers of people with Alzheimer disease: The LASER-AD study. American Journal of Geriatric Psychiatry. 2005; 13(9):795-801.

[7] Aguglia E, Onor ML, Trevisiol M, Negro C, Saina M, Maso E. Stress in the caregivers of Alzheimer's patients: An experimental investigation in ltaly. American Journal of Alzheimer's Disease and Other Dementias. 2004; 19(4):248-52.

[8] Vitaliano PP, Katon WJ. Effects of stress on family caregivers: recognition and management. Psychiatric Times. 2006; 23(7):24.

[9] Bastani F, Hosseiny R, Baniasad M, Haghni H. [Investigation of General Health in Female Care givers of Elderly People with Alzheimer (Persian)]. Iranian Journal of Ageing. 2010; 5(3):43-51.

[10] Turkington C. Stress management for busy people [R. Balali \& F. Baezzat, Persian trans]. Tehran: Be'sat Publication; 2010.

[11] Vlaeyen JW, Crombez G, Goubert L. The psychology of chronic pain and its management. Physical Therapy Reviews. 2007; 12(3):179-88.

[12] Alloy LB, Riskind JH. Cognitive vulnerability to emotional disorders. New Jersey: Lawrence Erlbaum Associates; 2006.

[13] Tremblay PF, King PR. State and trait anxiety, coping styles and depression among psychiatric inpatients. Canadian Journal of Behavioral Science. 1994; 26(4):505-519.

[14] Franken IH, Hendriks VM, Haffmans PM, van der Meer CW. Coping style of substance-abuse patients: Effects of anxiety and mood disorders on coping change. Journal of Clinical Psychology. 2001; 59(3):299-306.

[15] Jan-Liopis E, Anderson P. Mental health promotion and mental disorder prevention across European Member States: A collection of country stories. $2^{\text {nd }}$ ed. Luxembourg: European Communities; 2006.

[16] Wilks SE, Little KG, Gough HR, Spurlock WJ. Alzheimer's aggression: Influences on caregiver coping and resilience. Journal of Gerontological Social Work. 2011; 54(3):260-75.

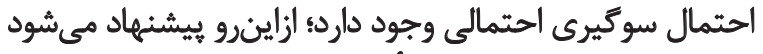

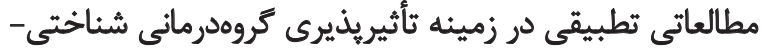

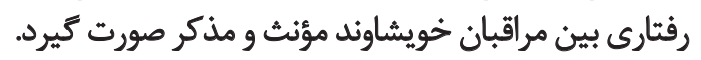

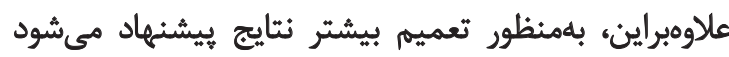

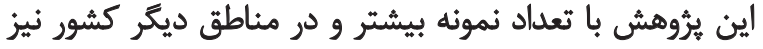

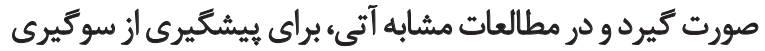

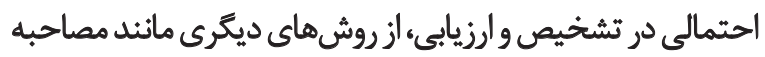

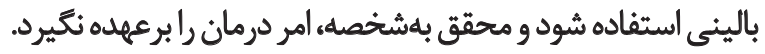

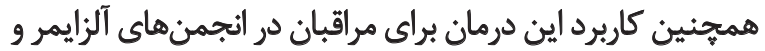

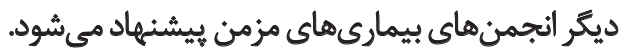

$$
\begin{aligned}
& \text { تشكر و قدرداني }
\end{aligned}
$$

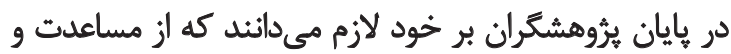

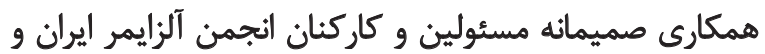
كليه شركت كنيدكان اين يثروهش تشكر و قدرداني نمايند. 
[17] Hollon SD. Cognitive therapy in the treatment and prevention of depression. In: Joiner JS, Brown J, editors. The Interpersonal, Cognitive and Social Nature of Depression. Mahwah, N.J.: Erjbaum; 2006

[18] Hamid N. The effectiveness of stress management based on cognitive-behavior method on depression, anxiety and fertilization of infertile women. Journal of Behavioral Sciences. 2011; 5(1):55-60.

[19] Ghasemzadeh Nasaji S, Paivastegar M, Hoseinian S, Moutabi F, Banihashemi S. Effectiveness of cognitive-behavioral intervention on coping responses and cognitive emotion regulation strategies. Journal of Behavioral Sciences. 2010; 4(1):35-43.

[20] Ashouri A, Mollazadeh J, Mohammadi N. [The effectiveness of cognitive-behavioral group therapy on the improvement of coping skills and relapse prevention in addicted individuals (Persian)]. Iranian Journal of Psychiatry and Clinical Psychology. 2008; 14(3):281-288.

[21] Foroozandeh N, Dalaram M. [Effects of cognitive behavioral therapy on the coping strategies of non-medical students of Shahrekord university of medical sciences (Persian)]. Journal of Shahrekord University of Medical Sciences. 2003; 5(3):26-34.

[22] Wesner AC, Gomes JB, Detzel T, Blaya C, Manfro GG, Heldt E. Effect of cognitive-behavioral group therapy for panic disorder in changing coping strategies. Comprehensive Psychiatry. 2014; 55(1):87-92.

[23] Hamdan-Mansour AM, Puskar K, Bandak AG. Effectiveness of cognitive-behavioral therapy on depressive symptomatology, stress and coping strategies among Jordanian university students. Issues in Mental Health Nursing. 2009; 30(3):188-9.

[24] Mosalanejad L, Khodabakshi Koolaee A, Jamali S. Effect of group cognitive behavioral therapy on hardiness and coping strategies among infertile women receiving assisted reproductive therapy. Iranian Journal of Psychiatry and Behavioral Sciences. 2012; 6(2):16-22.

[25] Losada A, Márquez-González M, Peñacoba C, Romero-Moreno R. Development and validation of the caregiver guilt questionnaire. International Psychogeriatrics. 2010; 22(4):650-60.

[26] Croog SH, Burleson JA, Sudilovsky A, Baume RM. Spouse caregivers of Alzheimer patients: Problem responses to caregiver burden. Aging and Mental Health. 2006; 10(2):87-100.

[27] McConaghy R, Caltabiano ML. Caring for a person with dementia: Exploring relationships between perceived burden, depression, coping and well-being. Nursing \& Health Sciences. 2005; 7(2):81-91.

[28] Calsbeek H, Rijken M, Bekkers MJT, Kerssens JJ, Henegouwen GPV, Dekker J. The Social Position of Adolescents and Young Adults with Chronic Digestive Disorders. European Journal of Gastroenterology \& Hepatology. 2002; 14(5):543-9.

[29] Sarason IG, Sarason BR. Abnormal psychology: The problem of maladaptive behavior [Y. Seyed Mohammadi, Persian trans]. $5^{\text {th }}$ ed. Tehran: Javaneh Roshd; 2002.

[30] Hawton K, Salkovskis PM, Joan Kirk J, Clark DM. Cognitive Behaviour Therapy for Psychiatric Problems: A Practical Guide [H. Ghasemzadeh, Persian trans]. Tehran: Arjmand Publication; 1998.
[31] Hasan Shahi M, Darayi M. [The impact of stress coping strategies on students' mental health (Persian)]. Knowledge \& Research in Applied Psychology. 2005; 26:77-98.

[32] Gross JJ, Munoz RF. Emotion regulation and mental health. Journal of Clinical Psychology. 1995; 5(2):64-151.

[33] Corey MS, Corey G. Groups: Process and Practice. [S. Bahari, Persian trans]. Tehran: Ravan Publication; 2002.

[34] Azad H. [Mental Pathology (Persian)]. Tehran: Be'sat Publication; 2007. 
